\title{
Intraoperative keratometry with the oval comparator (astigmometer)*
}

\author{
S P AMOILS
}

From 'Johannesburg, South Africa

SUMmary The Astigmometer is a simple accessory which is attached to a surgical microscope. It allows precise suturing of the cataract wound and reduced the amount of postoperative astigmatism at six weeks. This allowed rapid visual rehabilitation and more active patients. It obviated the removal of sutures in the postoperative period in most patients $(90 \%)$. However, stable results after one year were obtained with selective suture cutting without the use of intraoperative keratometry. This was almost as good as in the astigmometer group, but the percentage of astigmatism less than 1 dioptre was reduced and that greater than 2 dioptres was increased.

With the advent of the intraocular lens and extended wearing of contact lenses rapid return of good vision without spectacles is possible if minimal astigmatism has been induced by the surgeon. Many authors have reported attempts to minimise postoperative astigmatism by using modified surgical techniques or the use of measuring devices to determine the amount of astigmatism induced on the operating table by the sutures. ${ }^{1-3}$ The most detailed reports are those describing the use of the Terry keratometer. ${ }^{+\infty}$ However, the cost, complexity, and difficulty in using this system has prevented more universal acceptance.

An attempt was made to develop a new type of instrument to determine intraoperative astigmatism and set up the wound so that the natural wound slippage would return the cornea to a near perfect shape.

\section{Theory and description of astigmometer}

The light source is a circular arrangement of highintensity light-emitting diodes attached to the operating microscope body. A self-illuminating ring in the focal plane of one eyepiece is rotated about its axis by means of a dial with a sterilisable cover. The oval produced is matched to that of the reflected light ring produced by the anterior corneal curvature. By

${ }^{*}$ Presented at the American International IOL Congress, Boston, Mass, 12 April 1985.

Correspondence to Dr S P Amoils, 1202 Medical Arts Building, Jeppe Street, Johannesburg, South Africa 2001. means of the principle of concentric or superimposed ovals a reading can be made.

When a circular ring of lights is reflected from the surface of the cornea, an estimation of the corneal astigmatism existing at that time can be made. If the incision is approximated too loosely, there is gaping of the wound edges. The radius of curvature, therefore, in the vertical meridian is longer than the radius of curvature in the horizontal meridian. This causes a 'flattening' of the cornea vertically and results in an 'against the rule' astigmatism. An elliptical reflex with the longer axis directed vertically demonstrates an 'against the rule' astigmatism (Fig. 1).

If the incision is closed too tightly, there is compression of the wound. The radius of curvature of the cornea in the vertical meridian becomes shorter than the radius of the curvature in the horizontal meridian. This causes a 'steepening' of the cornea vertically and results in a 'with the rule' astigmatism. An elliptical reflex with its shorter axis directed vertically shows a 'with the rule' astigmatism (Fig. 2).

Fig. 3 shows a standard operating microscope eyepiece which has been modified to include the 'Ovalometer'. It is an elegantly simple device that consists of nothing more than an illuminated ring member rotating about its axis in the focal plane of the eyepiece. This is illustrated by the circle of rotation of the circular member round its anchoring and rotatory shaft, which acts as a pivot. The focal plane of the eyepiece is the plane in which the viewed object is brought to focus. It is here that the surgeon sees the image of the circular ring of lights after it has 


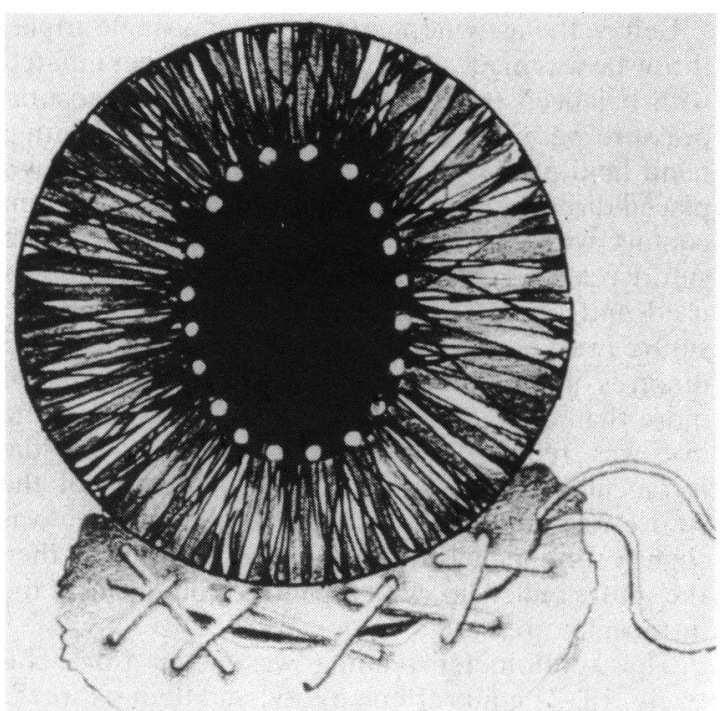

Fig. 1 Vertical reflected ring of light demonstrating 'against the rule' astigmatism. Suture too loose.

been reflected back by the anterior surface of the cornea acting as a convex mirror. It should be emphasised that any difference in the horizontal and vertical axis of the cornea will change the reflection of this circular ring of lights into an oval appearance.

Fig. 4 illustrates the mathematical relationship of the ring as it is rotated about its pivot and/or the ovals produced as seen by the surgeon looking in the

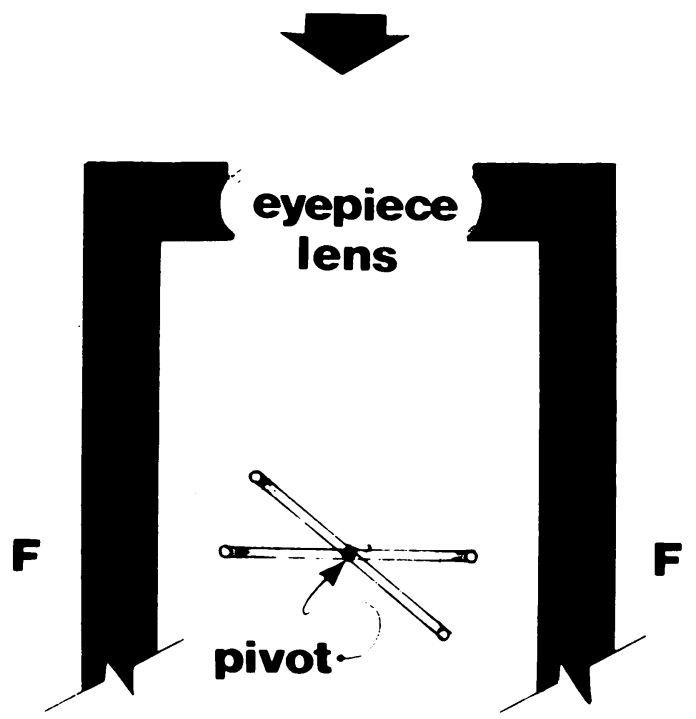

Fig. 3 Microscope eyepiece modified to include illuminated astigmometer showing rotation about its pivot.

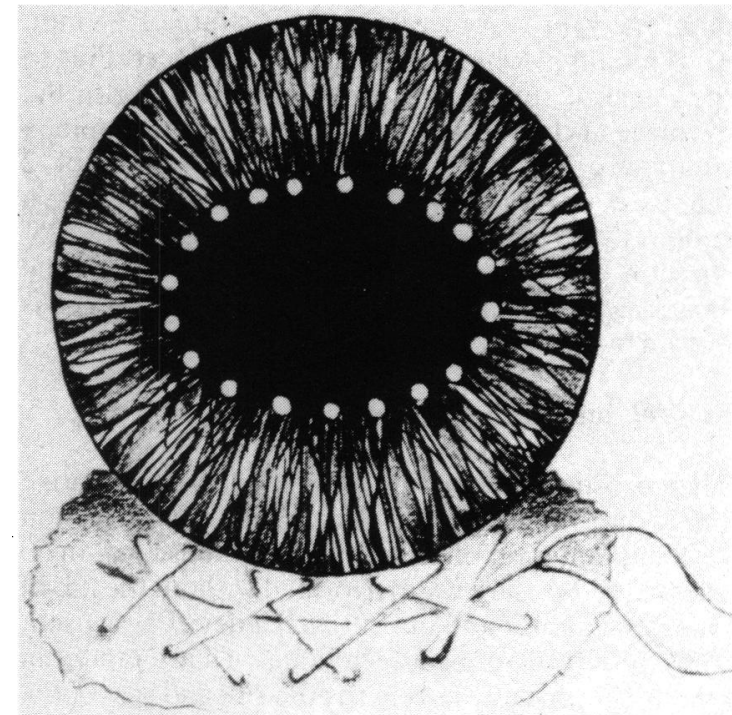

Fig. 2 Horizontal eliptical reflected light ring showing 'with the rule' astigmatism. Suture too tight.

direction of the large arrow. If the image of the inner circle of the viewing ring is projected on to the horizontal line, it makes a right angle with the plane. A triangle with a right angle has a hypotenuse, an adjacent side and an opposite side. The projected image seen in the focal plane is the adjacent side in a triangle and its length is defined by angle $\alpha$. Its length is calculated by the simple formula of cosine $\alpha$ multiplied by the length of the hypotenuse. As it is rotated from position 1 to position 2 it shortens as angle $\alpha$ increases. The hypotenuse represents 43

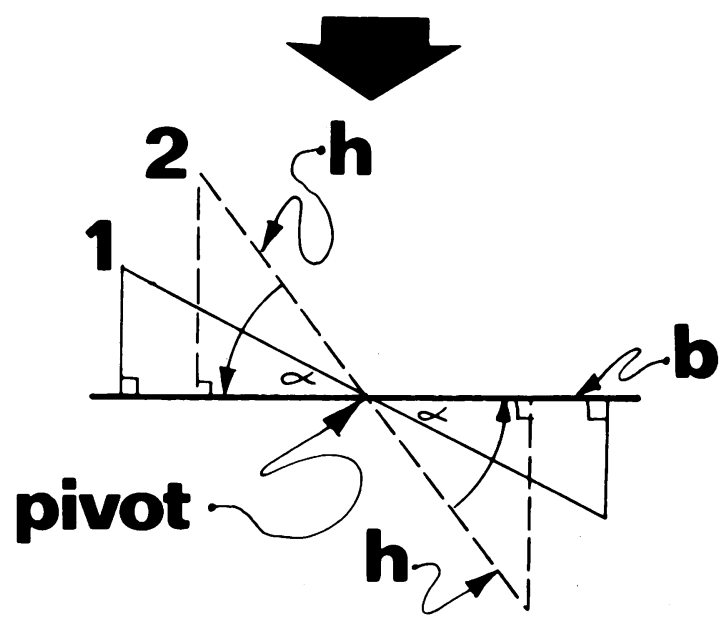

Fig. 4 Mathematical relationship of rotating illuminated ring showing the effect on the minor axis of the ellipse as seen by the surgeon looking into the eyepiece. 
dioptres of power or a radius of curvature of $7 \cdot 8 \mathrm{~mm}$. The amount by which astigmatism varies according to the angle of rotation of the illuminated ring in the eyepiece at the focal plane is shown. For example, a rotation of $17^{\circ}$ is equal to an astigmatism of 2 dioptres; a rotation of $20^{\circ}$ is equal to $2 \frac{1}{2}$ dioptres; a rotation of $21.5^{\circ}$ is equal to 3 dioptres, and a $25^{\circ}$ rotation produces 4 dioptres of astigmatism. If the axis is not horizontal, the long axis of the pivot is moved by rotating the eyepiece.

\section{Subjects and methods}

This prospective study included 200 consecutive cases of routine extracapsular cataract extraction with implantation of a posterior chamber lens. In 50 eyes wound closure was performed without the use of an astigmometer and on 150 such a device was used.

An identical surgical technique was attempted in all cases, especially as regards the site and size of the incision. A $12 \mathrm{~mm}$ arc (10 $\mathrm{mm}$ chord) three-plane incision was made, starting $1-1 \frac{1}{2} \mathrm{~mm}$ posterior to the surgical limbus, with a diamond knife. The flap was dissected with a hockey stick knife until well into clear cornea. The cornea was entered with a diamond knife and the incision enlarged with scissors (Fig. 5).

The wound was closed with a 9-0 nylon suture. This started on the scleral side at the right, and five crosses were made by the suture passing through the incision to the left and then back to end in the right corner of the wound. As the needle ended the suture on the corneal side of the incision on the right, the knot was tied so that it buried itself in the wound. The suture bites included the entire depth of the corneal flap; they started deep into the sclera under this flap, extended its whole width, and came out in intact sclera $1 \mathrm{~mm}$ distal to the first plane of the incision.

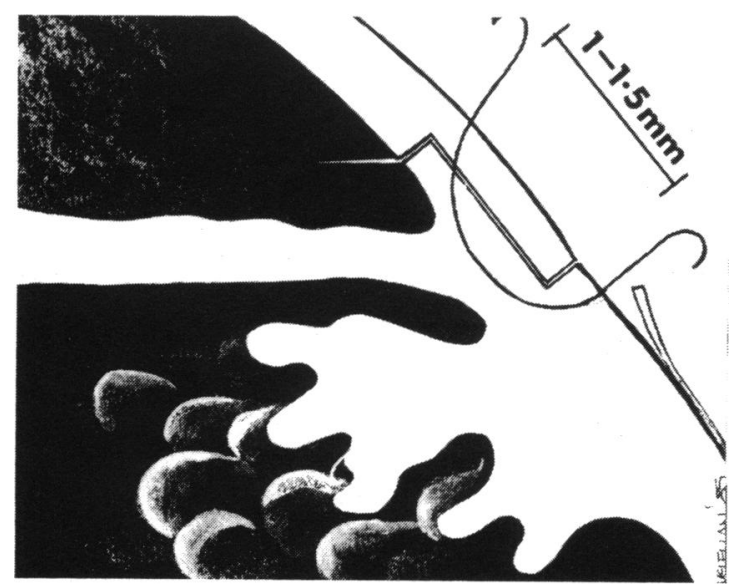

Fig. 5. Cross-section of eye showing surgical wound site and suture location.
Before the astigmometer was used a single triplethrow tie was made and the anterior chamber inflated with balanced salt solution (BSS). The intraocular pressure was set at between 15 and $25 \mathrm{mmHg}$ with a hand held plastic tonometer. The ring of light was placed directly on the apex of the cornea. Speculum contact with the eye was removed and the bridle suture released. In most cases a Schott speculum was used, and this prevented any pressure on the eye. The suture was adjusted to produce approximately 3 dioptres of astigmatism with the rule. If this required more than one attempt at loosening the suture, the eye was reflated with BSS every time and the intraocular pressure checked. If tightening of the suture was required for the procedure, the eye was slightly softened by an anterior chamber tap and then the suture pulled up, with repeated monitoring of the intraocular pressure.

The keratometer reading was taken preoperatively, 18-24 hours after surgery, and then six weeks and thereafter for one year. A Nikon keratometer using the Helmholtz principle of doubling was used in all cases. Careful suture cutting was begun at six weeks in cases of severe astigmatism greater than 2 dioptres. This was performed at weekly stages, as steroid drops were used in the first four weeks postoperatively, with weak steroid drops continued for two months. These readings were used to determine the amount of preoperative and postoperative corneal astigmatism as well as the astigmatic decay that occurs during the postoperative phase. ${ }^{3}$

\section{Results}

Table 1 shows a comparison of the astigmatism in the two groups. The results at the six-week interval before suture removal show a significant difference between the groups using the astigmometer and the control group (Table 2). The mean six-week postoperative astigmatism was 1.08 dioptres in the astigmometer group and 3.41 dioptres in the control group. Selective suture cutting was then begun in the control cases and astigmometer cases where the astigmatism was greater than 2 dioptres. This was done in one to three stages at weekly intervals. Only $6 \%$ of the astigmometer group had astigmatism greater than 3 dioptres six weeks after surgery as compared with $30 \%$ of the control group, and

Table 1 Preoperative astigmatism (200 cases)

\begin{tabular}{lc}
\hline Dioptres & Percentage \\
\hline 0 to 1 & $68 \%$ \\
$>1$ to 2 & $21 \%$ \\
$>2$ to 3 & $8 \%$ \\
$>3$ & $3 \%$ \\
\hline
\end{tabular}


Table 2 Postoperative astigmatism six weeks after surgery, before suture removal

\begin{tabular}{lcc}
\hline $\begin{array}{l}\text { Astigmatism } \\
\text { (dioptres) }\end{array}$ & $\begin{array}{l}\text { Control } \\
\text { (50eyes) }\end{array}$ & $\begin{array}{l}\text { Ovalometer } \\
\text { (150 eyes) }\end{array}$ \\
\hline 0 to 1 & $16(32 \%)$ & $91(61 \%)$ \\
$>1$ to 2 & $10(20 \%)$ & $44(29 \%)$ \\
$>2$ to 3 & $9(18 \%)$ & $9(6 \%)$ \\
$>3$ & $15(30 \%)$ & $6(4 \%)$ \\
\hline
\end{tabular}

changes of up to 10 dioptres were found in the latter group (Table 2). The mean astigmatic change from the astigmometer readings during surgery was 2.96 dioptres in the first six weeks. This figure shows a mean keratometric decay of almost 3 dioptres with the rule in this period. It illustrates a stretching or slipping of the wound in the vertical meridian of $7 \%$, represented by the difference of the $y$ and $x$ axis of the oval as measured by the astigmometer.

\section{Discussion}

The data show the great difference in postoperative astigmatism between the two groups of cases after six weeks. The wound slippage of $7 \%$ in the first six weeks is clearly illuminated by the data obtained from the astigmometer group. Clearly the wound stretching occurs at right angles to the centre portion of the cataract incision, and this is confirmed by the astigmometer findings. It is almost certainly influenced by the concentration and duration of the steroid used. All cases done had a subconjunctival injection of methylprednisolone acetate (DepoMedrol) at the end of surgery $(0.3 \mathrm{ml})$ as well as six weeks of dexamethasone $\mathbf{0 . 1 \%}$ (Spersadex) drops, and $95 \%$ were given prednisolone acetate $1 \%$ (Pred Forte) drops during this period. Steroids were continued for another six weeks, but weaker concentra-

Table 3 Astigmatism: 12 months after surgery

\begin{tabular}{lcc}
\hline $\begin{array}{l}\text { Astigmatism } \\
\text { (dioptres) }\end{array}$ & $\begin{array}{l}\text { Control } \\
\text { (50eyes) }\end{array}$ & $\begin{array}{l}\text { Ovalometer } \\
\text { (150eyes) }\end{array}$ \\
\hline 0 to 1 & $26(52 \%)$ & $87(58 \%)$ \\
$>1$ to 2 & $16(32 \%)$ & $48(32 \%)$ \\
$>2$ to 3 & $4(8 \%)$ & $9(6 \%)$ \\
$>3$ & $4(8 \%)$ & $6(4 \%)$ \\
\hline
\end{tabular}

tions were used, namely fluromethalone $0 \cdot 1 \%$ (FML).

The cornea can be likened to a ball that has been distorted by the sutures compressing the wound. Its elastic modulus and intraocular pressure attempt to restore its original shape, which is prevented by tight sutures but aided by all factors which delay wound healing. In all cases of astigmatism greater than 2 dioptres the sutures were carefully cut in stages starting with the suture at the extreme end of the wound nearest to the knot. This was followed by the suture at the other end of the wound in one week and then one or two central cuts, a week later, if required.

The reason only 50 cases were done as a control as compared with the 150 cases on the astigmometer is that the latter patients were so much happier that the use of further controls was thought to be ethically unjustifiable. The ability of the surgeon to measure the tightness of his suture line will certainly allow him to improve his individual technique.

The results after one year showed much less difference in the amount of astigmatism (Table 3 ). This finding shows that with great care in the cutting of the suture in cases of excess astigmatism good results can be obtained. The percentage of cases with small (less than 1 dioptre) astigmatism, however, is reduced, and the percentage of astigmatism greater than 2 dioptres is increased.

\section{References}

1 Troutman RC, Kelly S, Kaye D, Clahane AC. The use and preliminary results of the Troutman surgical keratometer in cataract and corneal surgery. Ophthalmology (Rochester) 1977; 83: 232-8.

2 Jaffe NS, Clayman HM. The pathophysiology of corneal astigmatism after cataract extraction. Ophthalmology (Rochester) 1975; 79: 615-21.

3 Cravy TV. Calculation of the changes in corneal astigmatism following cataract extraction. Ophthalmic Surg 1979; 10: 38-41.

4 Colvard DM, Kratz RP, Mazzocco TR, Davidson B. Clinical evaluation of the Terry surgical keratometer. ASIOISJ 1980; 6: 249-51.

5 Colvard DM, Kratz RP, Mazzocco TR, Davidson B. The Terry surgical keratometer: a 12 month follow-up report. AIOISJ 1981 7:348-50.

6 Terry C. Surgical keratometry and optics of corneal alteration. In eds. Keratorefraction, Schacher RA, Levy NS, Schacher L. Denison, Texas, LAL: 1980: 15-25.

Accepted for publication 30 December 1985. 